\title{
Penyuluhan Pencegahan Tuberkulosis untuk Meminimalisasi Penularan pada Masyarakat Lanjut Usia di Kabupaten Serdang Bedagai
}

\author{
Dicky Yuswardi Wiratma', Tiara Rajagukguk \\ ${ }^{1}$ Fakultas Farmasi dan IImu Kesehatan Universitas Sari Mutiara Indonesia \\ Jl. Kapten Muslim No.79 Medan 20123, Indonesia
}

\author{
ARTICLE INFO: \\ Received: 2020-05-29 \\ Revised: 2020-07-04 \\ Accepted: 2020-09-11
}

Keywords:

Counseling; Elderly; Infectious diseases; Tuberculosis

\begin{abstract}
Pulmonary tuberculosis is one of the highest prevalence of infectious diseases in the world. More than $90 \%$ of TB cases and deaths come from developing countries, one of which is Indonesia. The village of Tanjung Harap in Serdang Bedagai Regency still has a high rate of tuberculosis in the elderly. This can occur because of the low awareness of healthy living and knowledge about pulmonary tuberculosis. This counseling activity is intended so that the community, especially the elderly, know the dangers of pulmonary TB infectious diseases and know the precautions and when symptoms have arisen. Counseling was carried out by means of questionnaires, lectures, and video screenings about prevention and what actions should be taken as prevention of infectious diseases, especially pulmonary tuberculosis, this activity ends with blood pressure checks and vital signs. The results of this counseling showed a positive impact and increased knowledge to protect themselves and prevent the transmission of pulmonary tuberculosis in the elderly. Based on the results of the activities carried out, it can be concluded that this has an influence on the insight, knowledge and concern of the community, especially the elderly who are in the village of Tanjung Harap Serdang Bedagai Regency.
\end{abstract}

(C) 2020 Published by University of Merdeka Malang. This is an open access article distributed under the CC BY-SA 4.0 license (https://creativecommons.org/licenses/by-sa/4.0/)

How to cite: Wiratma, D. Y., \& Rajagukguk, T. (2020). Penyuluhan Pencegahan Tuberkulosis untuk Meminimalisasi Penularan pada Lansia di Desa Tanjung Harap Kabupaten Serdang Bedagai. Abdimas: Jurnal Pengabdian Masyarakat Universitas Merdeka Malang, 5(3), 294-299. https://doi.org/10.26905/abdimas.v5i3.4227

\section{PENDAHULUAN}

Tuberkulosis paru adalah suatu penyakit yang disebabkan oleh bakteri/kuman Mycobacterium tuberculosis. Kuman tersebut masuk ke dalam tubuh manusia melalui percikan air ludah (droplet) dan dapat menyebar kebagian tubuh lain melalui sistem peredaran darah, sistem saluran limfe, saluran nafas (bronchus) atau penyebaran langsung ke bagian-bagian tubuh lainnya (Wasilah, 2001).

Gejala tuberkulosis paru yang tampak adalah batuk terus menerus dengan dahak selama tiga minggu atau lebih. Kadang-kadang dahak yang keluar bercampur dengan darah. Sesak nafas dan rasa 


\section{Penyuluhan Pencegahan Tuberkulosis untuk Meminimalisasi Penularan pada Masyarakat Lanjut Usia...}

Dicky Yuswardi Wiratma ${ }^{1}$, Tiara Rajagukguk

nyeri di dada. Badan lemah, nafsu makan menurun, berat badan menurun. Berkeringat malam hari walau tanpa aktivitas. Demam meriang (demam ringan) lebih dari satu hari (Laban, 2008).

Tanda dan ciri yang mudah untuk diketahui saat orang terkena TBC biasanya selalu berkeringat di malam hari tanpa penyebab sesuatu yang jelas. Biasanya pengobatan penyakit TB ini tidak akan sembuh dengan cepat, butuh waktu 6 hingga 9 bulan untuk proses penyembuhan (Misnadiarly, 2006).

Mencegah penyakit tentu lebih baik daripada mengobati. Dengan mejalankan pola hidup sehat dan menjaga lingkungan yang sehat merupakan kunci agar kita terhindar dari berbagai macam penyakit tak terkecuali penyakit TBC. Untuk itu sangat perlu menjaga lingkungan yang sehat seperti pengaturan syarat-syarat rumah yang sehat di antaranya luas bangunan rumah, ventilasi, pencahayaan dengan jumlah anggota keluarga, kebersihan lingkungan tempat tinggal. Melalui pemberdayaan keluarga sehingga anggota rumah yang lain dapat turut serta dan berperan dalam melakukan pengawasan terhadap si penderita dalam minum obat. Ada baiknya bagi seorang yang sehat menghindari kontak bicara pada jarak yang dekat dengan penderita TB paru atau bisa menggunakan masker, namun hal ini masih tetap rentan. Bila penderita TB paru batuk atau bersin, sebaiknya orang yang sehat menutup mulut. Satu hal yang perlu diperhatikan, yaitu arah angin. Jangan sampai angin berhembus mengarah ke orang yang sehat setelah sebelumnya melalui orang yang menderita TB paru. Bukan mencegah arah anginnya, namun kita yang harus menghindari angin tersebut yang bisa merupakan angin karena alam atau angin karena kipas angin dan lainnya (Hudoyo, 2002).

Sejak tahun 1980 penyakit TB paru mendapat perhatian dan prioritas WHO. Tingginya angka kesakitan dan kematian akibat TB paru disebabkan oleh berbagai faktor antara lain rendahnya penghasilan, kepadatan penduduk, tingkat pendidikan yang rendah, serta pengetahuan kesehatan yang kurang dari masyarakat. Disamping itu, masih tingginya morbiditas dan mortalitas TB paru oleh karena kekurangan dalam hal cakupan pengobatan TB paru dan kegagalan pengobatan (Fahrudda, 2001).

Tuberkulosis paru merupakan salah satu penyakit infeksi yang prevalensinya paling tinggi di dunia. Berdasarkan laporan World Health Organitation (WHO, 2012) sepertiga populasi dunia yaitu sekitar dua milyar penduduk terinfeksi Mycobacterium Tuberculosis. Serta dari 8 juta populasi, terkena TB aktif setiap tahunnya dan 2 juta meninggal dunia. Lebih dari 90\% kasus TB dan kematian berasal dari negara berkembang salah satunya Indonesia (Depkes RI, 2012).

Indonesia saat ini berada pada rangking kedua Negara dengan beban TB paru tertinggi di dunia setelah India. Dalam laporan Tuberkulosis Global 2014 dirilis oleh laporan World Health Organitation (WHO) disebutkan insidensi di Indonesia pada angka 460.000 kasus baru per tahun. Namun di tahun 2015, angka tersebut sudah direvisi, yakni naik menjadi juta kasus per tahun. Persentase jumlah kasus di Indonesia pun menjadi $10 \%$ terhadap seluruh kasus di dunia sehingga menjadi negara dengan kasus terbanyak kedua setelah India. Negara India menempati urutan pertama dengan presentasi kasus $23 \%$ di seluruh dunia (WHO, 2015).

Berdasarkan data profil kesehatan yang dilaporkan oleh Dinas Kesehatan Provinsi Sumatera Utara (2013-2015) menjelaskan bahwa jumlah penderita TB Paru yang terdata pada tahun 2013 yaitu sebanyak 21.954 penduduk Sumatera Utara atau sebesar 120,5\% dan menurun pada tahun 2014 menjadi sebanyak 19.062 penduduk Sumatera Utara atau sebesar 111\%, namun meningkat pada tahun 2015 menjadi sebanyak 23.002 penduduk Sumatera Utara atau sebesar 122\%. Jumlah angka kesembuhan di Provinsi Sumatera Utara menurut data Dinkes Prov. Sumut tahun 2013-2015 terdapat 16.474 penduduk atau sebesar 91\% pada tahun 2013, menurun menjadi 14.742 penduduk atau sebesar 87,1\% pada tahun 2014 dan meningkat 
ABDIMAS: Jurnal Pengabdian Masyarakat Universitas Merdeka Malang

Volume 5, No 3, November 2020: 294-299

pada tahun 2015 menjadi sebanyak 14.901 penduduk atau sebesar 87,9\%. Walaupun terjadi penurunan angka kesembuhan dari tahun 2013-2015, tetapi angka ini sudah mencapai target yang ditetapkan oleh pemerintah sebesar 85\% (Dinkes Prov Sumut, 2016).

Salah satu desa di Kabupaten Serdang Bedagai yaitu Desa Tanjung Harap masih memiliki angka kesakitan penyakit tuberkulosis yang tergolong tinggi. Hal ini dapat terjadi karena masih rendahnya kesadaran untuk hidup sehat di kalangan masyarakat desa tersebut, dan masih kurangnya pengetahuan masyarakat tentang penyakit menular khususnya tuberkulosis paru.

Menurut Andarmoyo \& Nurhayati (2018), bahwa meningkatnya kasus TB paru di Kabupaten Ponorogo adalah karena masih kurangnya pelatihan untuk meminimalisasi penularan TB paru dan kurangnya pemahaman serta peran dan tugas PMO (Pengawas Menelan Obat).

Berdasarkan latar belakang dan data di atas maka penulis tertarik melakukan pengabdian masyarakat untuk melakukan penyuluhan pencegahan tuberkulosis paru untuk meminimalisasi penularan pada orang lanjut usia di Desa Tanjung Harap Kabupaten Serdang Bedagai.

Kegiatan penyuluhan ini bertujuan agar masyarakat khususnya orang lanjut usia mengetahui bahaya penyakit menular TB paru serta mengetahui tindakan apa yang dapat dilakukan untuk pencegahan dan apabila telah timbulnya gejala.

\section{METODE}

\section{Tempat dan Waktu Pelaksanaan}

Kegiatan ini dilakukan di gedung aula Desa Tanjung Harap Kabupaten Serdang Bedagai. Pelaksanaannya meliputi kegiatan promotif dan preventif dengan melibatkan tim pengabdian dengan metode survey, kuesioner, ceramah, diskusi dan pemeriksaan kesehatan. Program penyuluhan ini diikuti oleh masyarakat mayoritas orang lanjut usia sebanyak 22 orang dan dilaksanakan pada bulan Mei 2019.

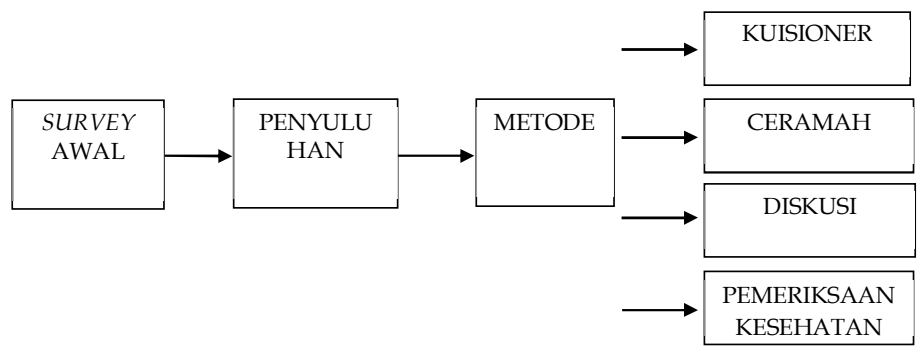

Gambar 1. Bagan metode kegiatan

\section{Proses Kegiatan}

Pada penyuluhan ini acara dimulai dengan pertemuan dan perkenalan dengan kepala desa beserta staff perangkat desa. Kemudian dilanjutkan dengan perkenalan tim pengabdian kepada para peserta (Gambar 2). Penyuluhan ini dilakukan dengan metode kuesioner untuk melihat wawasan dan pengetahuan peserta dan dilanjutkan dengan ceramah dan pemutaran video mengenai pencegahan dan tindakan apa yang harus dilakukan sebagai pencegahan penyakit menular khususnya tuberkulosis paru, para peserta juga banyak yang tertarik untuk bertanya mengenai materi penyuluhan ini (Gambar 3), pemberian informasi 


\section{Penyuluhan Pencegahan Tuberkulosis untuk Meminimalisasi Penularan pada Masyarakat Lanjut Usia...}

Dicky Yuswardi Wiratma ${ }^{1}$, Tiara Rajagukguk

ini di maksudkan untuk menambah wawasan peserta, dan kegiatan ini diakhiri dengan post test dan pemeriksaan tekanan darah dan vital sign untuk memantau kesehatan peserta untuk dapat ditindaklanjuti agar mendapatkan penanganan yang tepat.
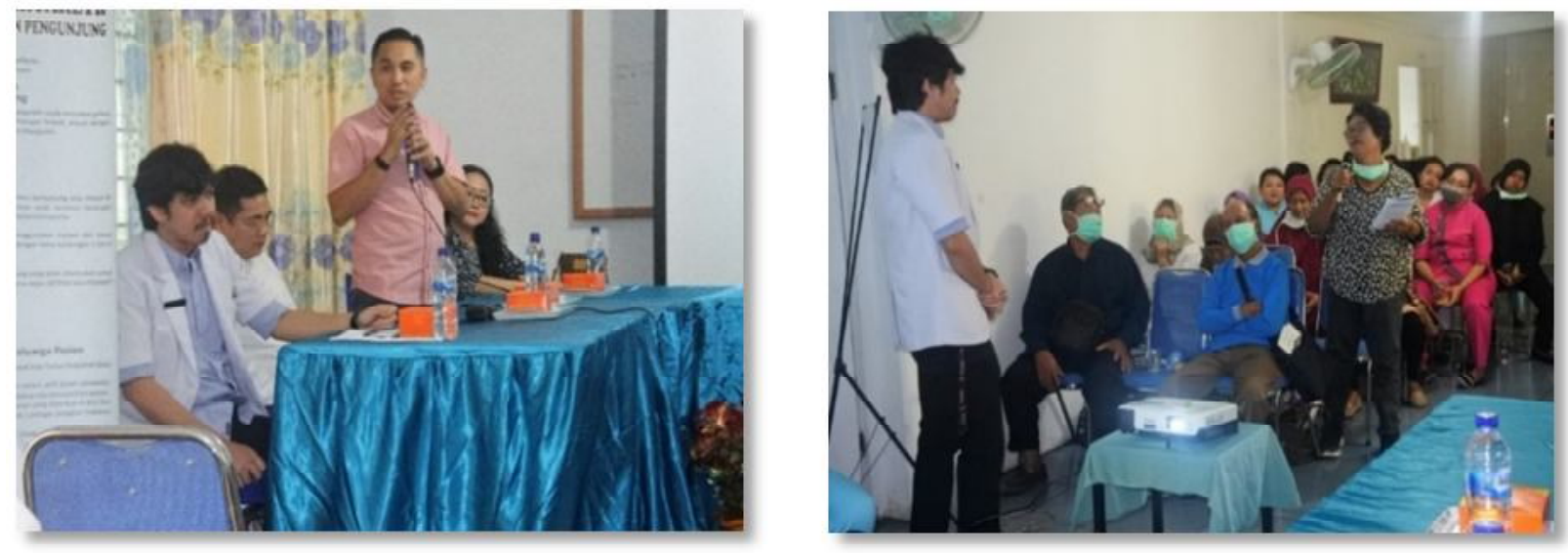

Gambar 2. Perkenalan tim pengabdian

Gambar 3. Penyuluhan dan interaksi peserta

\section{HASIL DAN PEMBAHASAN}

\section{Hasil}

Sebagian besar peserta menemukan kesadaran akan pentingnya mengikuti kegiatan penyuluhan ini sebagai bentuk kepedulian terhadap pencegahan penyakit menular. Hal ini berdampak positif pada masyarakat Desa Tanjung Harap khususnya pada orang lanjut usia. Dari Gambar 4 dapat dilihat hasil kuesioner pre-test dan Gambar 5 post-test penyuluhan ini, menunjukkan adanya peningkatan pengetahuan bahwa pentingnya untuk menjaga kebersihan diri dan mencegah penularan tuberkulosis paru.
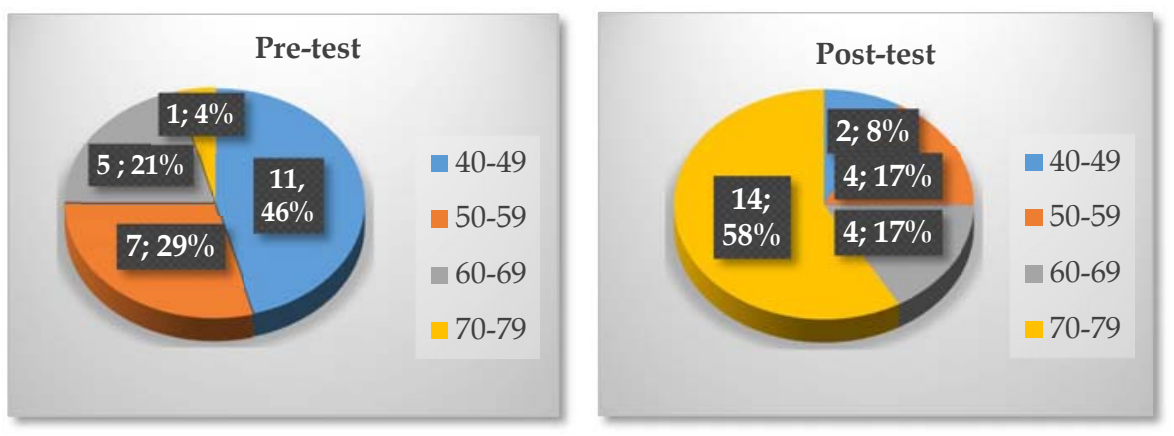

Gambar 4. Hasil pre-test sebelum diberikan materi penyuluhan

Gambar 5. Hasil post-test sesudah diberikan materi penyuluhan

\section{Pembahasan}

Kegiatan pengabdian ini memberikan wawasan dan pengetahuan yang lebih luas serta pengaruh yang baik bagi para peserta. Hal ini dapat dilihat dan dibuktikan dari antusiasme para peserta yang 
ABDIMAS: Jurnal Pengabdian Masyarakat Universitas Merdeka Malang

Volume 5, No 3, November 2020: 294-299

mengikuti penyuluhan ini, yang pada awalnya kurang paham dan kurang perduli terhadap pencegahan diri sendiri, setelah mengikuti kegiatan ini mereka sangat aktif untuk bertanya mengenai cara pencegahan dan tindakan apa yang harus dilakukan untuk meminimalisasikan penularan.

Berdasarkan hasil penelitian Ernawati et al. (2018), penyuluhan pencegahan penularan tuberkulosis memiliki dampak dalam meningkatkan pengetahuan tentang pencegahan penularan TB paru sebesar $85,7 \%$ dan tentang cara penggunaan masker sebesar 100\%. Kholis juga merekomendasikan agar dilakukannya edukasi secara kontinu agar dapat membentuk sikap dan perilaku hidup bersih.

\section{SIMPULAN DAN SARAN}

\section{Simpulan}

Berdasarkan hasil kegiatan pengabdian masyarakat mengenai penyuluhan pencegahan tuberkulosis paru untuk meminimalisasi penularan di Desa Tanjung Harap Kabupaten Serdang Bedagai, maka dapat disimpulkan bahwa penyuluhan penyakit menular ini memiliki pengaruh terhadap wawasan dan menambah pengetahuan serta kepedulian masyarakat khususnya orang lanjut usia yang ada di Desa Tanjung Harap Kabupaten Serdang Bedagai.

\section{Saran}

Masyarakat khususnya orang lanjut usia lebih diutamakan dalam pemberian informasi mengenai penyakit menular karena di usia yang sudah lanjut maka kemungkinan untuk terjadi penularan akan lebih besar, diharapkan bagi perangkat desa juga berperan aktif dalam melakukan penyuluhan kepada penduduknya.

\section{DAFTAR PUSTAKA}

Andarmoyo, S., \& Nurhayati, T. (2018). Pelatihan dan pendampingan PMO (Pengawas Menelan Obat) dalam minimalisasi penularan tuberkolosis paru di Kabupaten Ponorogo. Laporan Akhir IPTEKS bagi Masyarakat (IbM) Internal Tahun Anggaran 2015/2016.

Depkes RI. (2012). Pedoman Nasional Penanggulangan Tuberculosis. Jakarta: Depkes RI.

Dinkes Provinsi Sumatera Utara. (2016). Profil Kesehatan Provinsi Sumatera Utara Tahun 2015. Dinkes Sumatera Utara. Medan.

Ernawati, K., Rifqatussa'adah, R., Wulansari, R., Damayanti, N. A., \& Djannatun, T. (2018). Penyuluhan tentang cara pencegahan penularan TB dan pemakaian masker kepada keluarga penderita TB di Johar Baru, Jakarta Pusat. Berita Kedokteran Masyarakat, 34(1), 44.

https://doi.org/10.22146/bkm.32108

Fahrudda, A. (2001). Faktor-Faktor yang Mempengaruhi Keberhasilan Pengobatan Tuberkulosis. Banjarmasin: Pusat Studi Tuberkulosis, FK Unlam, RSUD Banjarmasin, Tuberkulosis Tinjauan Multidisiplin.

Sumirat, S. (2017). 30 Jenis Penyakit Menular dan Pencegahannya. JPKM Surya Sumirat. https://www.jpkmsuryasumirat.com/index.php/berita/artikel/107-30-jenis-penyakit-menularpenyebab-dan-pencegahannya (diakses pada tanggal 7 Juni 2019). 
Penyuluhan Pencegahan Tuberkulosis untuk Meminimalisasi Penularan pada Masyarakat Lanjut Usia... Dicky Yuswardi Wiratma ${ }^{1}$, Tiara Rajagukguk

Hudoyo, A. (2002). Tuberkulosis. Jakarta: Penerbit Universitas Indonesia.

Laban, Y. Y. K. (2008). TBC Penyakit \& Cara Pencegahannya. Yogyakarta: Kanisius.

Misnadiarly. (2006). Penyakit Infeksi TB Paru. Jakarta: Penerbit Pustaka Populer Obor.

Wasilah, S. (2001). Hepatitis Karena Obat-Obatan Tuberkolosis. Banjarmasin: Pusat Studi Tuberkulosis, FK Unlam, RSUD Banjarmasin, Tuberkulosis Tinjauan Multidisiplin.

World Health Organization (WHO). (2015). Global Tuberculosis Report. Geneva. 